\title{
Review on Extraction and Isolation of Plant Secondary Metabolites
}

\author{
Marie I. NGAHA NJILA ${ }^{1}$, Ebrahimi MAHDI ${ }^{2}$, Dieudonne MASSOMA LEMBE ${ }^{3}$ Zacharie NDE ${ }^{4}$, Doriane \\ NYONSEU ${ }^{5}$
}

\begin{abstract}
The use of plant metabolites for medicinal and cosmetic purpose is today gaining popularity. The most important step in this exploitation of metabolites is extraction and isolation of compound of interest. These day we can identified two group of extraction technique called conventional technique using cheaper equipment, high amount of solvent and takes long extracting time, and new or green technique using costly equipment, elevated pressure and / or temperatures with short extracting time. After extracting secondary metabolites a step of purification and isolation are required using Chromatographic or Non- Chromatographic techniques. This paper reviews the different technique of extraction and identification of plant metabolites.
\end{abstract}

Keywords: plant metabolites, extraction, isolation, conventional technique, green technique.

\section{INTRODUCTION}

Plants materials are on increasing interest for their applications in pharmaceutical, nutritional and cosmetic application. They represent a source of active ingredients known for long times ago by its traditional used for medical purposes. Plants can be consider as an origin of natural ingredients useful in medicine and other purposes. Plants are rich in active compounds or secondary metabolites such as alkaloids, steroids, tannins, glycosides, volatile oils, fixed oils, resins, phenols and flavonoids which are present in their organs such as leaves, flowers, bark, seeds, fruits, root, etc. Extraction processes of these metabolites are related to the difference in solubility of the compounds present in a mixture of solvent. The beneficial action of those phytoconstituents typically come from the merging or synergic work of these secondary products (Tonthubthimthong et al., 2001).

Marie I. NGAHA NJILA : Department Of Animal Sciences, Faculty Of Science, University Of Douala, Cameroon/ Department Of Veterinary Preclinical Sciences, Faculty Of Veterinary Medicine, Universiti Putra Malaysia,43400 UPM SERDANG, SELANGOR, MALAYSIA; ngahamarie@yahoo.fr; +601113006372

Ebrahimi MAHDI DEPARTMENT OF VETERINARY PRECLINICAL SCIENCES, FACULTY OF VETERINARY MEDICINE, UNIVERSIT I PUTRA MALAYSIA,43400 UPMSERDANG, SELANGOR, MALAYSIA; Dieudonne MASSOMA LEMBE DEPARTMENT OF ANIMAL SCIENCES, FACULTY OF SCIENCE, UNIVERSITY OF DOUALA, CAMEROON; pmasso@yahoo.fr

Zacharie NDEDEPARTMENT OF ANIMAL SCIENCES, FACULTY OF SCIENCE, UNIVERSITY OF DOUALA, CAMEROON; zachariende@yahoo.fr

Doriane NYONSEU DEPARTMENT OF ANIMAL SCIENCES, FACULTY OF SCIENCE, UNIVERSITY OF DOUALA, CAMEROON; nyonseucamilledoriane@yahoo.fr
There are several extractions techniques for metabolites present a vegetal. These techniques can be called conventional (long been used) and new (developed more recently). Conventional techniques are the ones using organic fluid (hexane, acetone, methanol, ethanol etc.) or water and are carried out generally at atmospheric pressure while new techniques using pressure and / or elevated temperatures (Luque de Castro et al., 1998). Methods used for extraction are necessary for the differentiation of active components of plant tissues from the originated components by using appropriated solvents. During this process, the solvents move into the solid plant material and solubilize the compounds with similar polarity (Amita and Shalini; 2014). Thus the need in choosing the relevant extraction method is evident because when different methods are practiced on same plant material with the same solvent, extraction efficiency show significant variations. In addition, the relevant extraction methods most be constant, for a future good reproducibility. More, appropriate solvent is of essential importance along with application. This is related to fact that polar solvents will extract out polar actifs compounds and non-polar ones will be extracted out by non-polar solvents (Ankit et al., 2012).

For the extraction prodecures, solvents such as water, ethanol, chloroform, ethyl acetate, methanol, etc. are commonly used and occasionally, for a better extraction efficiency, mixtures of solvents can be used. Among the conventional techniques, there are the traditional solid-liquid extraction methodologies, such as Decoction, Infusion, Soxhlet extraction, Maceration and Hydrodistillation. Increase in the interest of plant metabolites has encourage researchers to an increasing consideration for novels methods of extraction enabling fastening and shortening extraction times, efficient extraction, automation, and reduction of organic solvent consumption (Rafiee et al ., 2011). Several novel extraction methods such as Ultrasound assisted extraction (UAE), Microwave assisted extraction (MAE), Supercritical fluid extraction (SFE) and pressurized liquid extraction (PLE) has took place. These new methods are able to reduce the extraction time, decrease the volume of solvent used and improve the extraction yield (Brusottia et al., 2014).

All these extractions procedure share have similar objectives:

- Extraction of targeted bioactive phytoconstituents from the vegetal;

- Increase the selectivity of analytical methods;

- Increase of sensitivity of bioassay by increasing the concentration of targeted compounds;

- Convert the bioactive compounds into a more suitable form for detection and separation;

Provide a strong and reproducible method that is independent of variations in the sample matrix (Smith; 2003). 


\section{Conventional technics}

Almost all these methods relied on the extracting capacity of the solvents use and the combining action of heat and/or mixing. To obtain bioactive compounds from plants, the conventional (classical) techniques commonly used are: Decoction, Infusion, Soxhlet extraction, Maceration and Hydrodistillation (Azmir ; 2013). All these methods use solvent, couple with elevated temperature and/or agitation.

\section{Decoction}

It a suitable method for the extraction of the constituents soluble in water and that cannot also been destroyed by the effect of heat (Bimakr ; 2010). During decoction, distilled water is added to the dried extract and the mixture is subjected to heating continuously for a period of time at a temperature of $100^{\circ} \mathrm{C}$. Then it is allowed to cool to room temperature and filtration is performed to obtain the filtrate. That filtrate is concentrated to obtained extract.

\section{Advantages and disadvantages}

This method does not required more and expensive equipment and it is easy to perform. Unfortunately it is not advised for the extraction of heat sensitive constituents.

\section{Infusion}

In this method, extraction consist in soaking the solids plants powder either cold or boiling water for a short period of time with (Bimakr ; 2010).

\section{Soxhlet extractor}

Soxhlet extraction is a method that was suggested for extraction of lipid first by Franz Ritter Von Soxhlet, a German chemist (Azmir; 2013). Nowadays, it is used for the extraction of valuable bioactive (solid-liquid) compounds from various natural sources. The Soxhlet extraction is a simple and convenient method for infinitely repeated cycle of extraction with a fresh solvent until complete exhaustion of the solute in the raw material (Grigonis et al., 2005).

During extraction with soxhlet, the process of distillation is implicated. It consist of heating a solution up to boiling and then condensed send back to the original flask (Bart; 2011). Practically, a limited quantity of dry material is introduced in a thimble. This thimble is then deposited in a distillation flask fill with specific solvent. After reaching to a submersion level, a siphon absorb the solvent in the thimble-holder and then release it back into the distillation flask. This solution contain the extracted solutes. This process is done continuously until the extraction is completed. (Azmir ; 2013).

The separation of the extract to the solvent is made using the device called Rotavapor. In this apparatus a vacuum evaporation is carried out using a vacuum pump with a check valve. During evaporation the ball is rotated and immersed in a heated liquid bath. The apparatus is fitted with a condensatecollecting flask. Rotation of the balloon creates a greater exchange surface and therefore renewed for performing rapid evaporation.
Advantages and disadvantages (Wang

et al., 2006;

Luque de Castro and Garcia-Ayuso ; 1998)

The advantages of Soxhlet extraction are:

The sample rapidly communicating with a portion fresh solvent, which helps to move the equilibrium to the transfer solvent;

This method does not require filtration after extraction.

The Soxhlet is independent of the matrix vegetable.

The disadvantages of this method, compared with the other conventional techniques are:

Long duration and high extraction amount of solvent consumed, which leads economic loss and the environmental problems.

The samples are heated to a high temperature for a relatively long period thus the risk of thermal destruction of some compounds cannot be overlooked if the plant material contains heat labile compounds.

Given the considerable amount of solvent used, the later stage evaporation / concentration becomes limiting.

\section{Maceration}

Maceration is an old technic used for medicinal preparation. It is consider as a widely and low-cost way to get phytochemical's from plant material. The maceration is a method is a solid-liquid extraction where the bioactive compound (solute) inside the plant material is extracted by soaking the plant material in a specific solvent for a period of time. The efficacy of maceration process is determined by two main factors, solubility and effective diffusion (Choon ; 2014).

Maceration involve three principals' steps. Firstly, plant materials is convert to powder form by grinding. This allow good contact between solvent and material the surface area for proper mixing with solvent. After grinding, a chosen solvent is added in a closed vessel. Then, the liquid is strained off but the solid residue of this extraction process is pressed to recover large amount of occluded solutions. During the process of maceration occasional shaking facilitate extraction by increasing diffusion and remove concentrated solution from the sample surface for bringing new solvent to the menstruum for more extraction yield (Azmir ; 2013).

\section{Advantages and disadvantages}

Maceration is a simple method using noncomplicated utensil and equipment and for this reason it is a popular choice for researchers. Unfortunately, the duration of extraction time is long and sometimes takes up to weeks (Choon ; 2014).

\section{Hydrodistillation}

Hydrodistillation is a traditional method for extraction of plants metabolites that doesn't used organic solvents. In hydrodistillation, plant materials are packed in a still compartment and water is added in sufficient amount, and then brought to boil. Alternatively, direct steam is injected into the plant sample. Hot water and steam act as the main influential factors to free bioactive compounds of plant tissue. Indirect cooling by water condenses the vapor mixture of water and oil. Condensed mixture flows from condenser to a 
separator, where oil and bioactive compounds separate automatically from the water (Silva et al., 2005).

The used of high extraction temperature can caused the lost some volatile components. This drawback limits its use for heat sensitive compound extraction. (Azmir ; 2013).

\section{New extraction techniques}

There are also call "Green extraction" related to the discovery and design of extraction processes with reduction of energy consumption, combine to the use of alternative solvents and renewable natural products which ensure a safe and high quality extract.

\section{Ultrasound assisted extraction (UAE)}

UAE is an inexpensive, fast, simple, less consuming energy and efficient extraction technique. The enhancement in extraction obtained by using ultrasound is mainly attributed to the effect of acoustic cavitations produced in the solvent by the passage of an ultrasound wave. Ultrasound also exerts a mechanical effect (ultrasonic waves break the cell walls), allowing greater penetration of solvent into the tissue, increasing the contact surface area between the solid and liquid phase. Then we assist in a situation where the solute quickly diffuses from the solid phase to the solvent (Tang-Bin Zou; 2011).

UAE extraction process depends on the particle sizes of plant extracts, the moisture content and the solvent used.

\section{Advantages and disadvantages}

The advantages of UAE include reduction in extraction time, energy and use of solvent. Ultrasound energy for extraction also facilitates more effective mixing, faster energy transfer, reduced thermal gradients and extraction temperature, selective extraction, reduced equipment size, faster response to process extraction control, quick start-up, increased production and eliminates process steps (Chemat et al., 2008).

The disadvantage of UAE is base to the fact that this technic has lower efficiency compare to other mew technic.

\section{Microwave-assisted extraction (MAE)}

The microwave-assisted extraction is a method used for extraction of soluble products into a fluid from a wide range of materials using microwave (non-ionizing electromagnetic fields in the frequency range from $300 \mathrm{MHz}$ to $300 \mathrm{GHz}$ ) energy. The principle of heating using microwave is based upon its direct impacts on polar materials. Electromagnetic energy is converted to heat following ionic conduction and dipole rotation mechanisms (Letellier and Budzinski ; 1999; Jain ; 2009). Microwaves penetrate into biomaterials and generate heat by interacting with polar molecules such as water inside the materials. Then the penetration of microwaves depth into plant matrix depends on dielectric constant, moisture content, temperature, and the frequency of the electrical field. The water contained in a plant material is responsible for the absorption of microwave energy which led to internal superheating and cell structure disruption. This action, created the diffusion of bioactive compound from the plant matrix (Takeuchi et al., 2009). The surrounding extraction solvent can remain cold if it dielectric constant is low and this can be advised for extraction of thermo sensitive compounds. Toluene and hexane are suggested for MAE because of their low dielectric constant compare to water, ethanol and methanol which are polar enough and able to strongly absorb microwaves energy. Also mixture of solvent is possible if the extracting selectivity and modulation of interaction between solvent and microwave energy is objected (Brachet et al., 2002).

The extraction mechanism of microwave assisted extraction involves three sequential steps. Firstly, solutes from active sites of sample matrix are separated under increased temperature and pressure; secondly, solvent diffused across sample matrix and thirdly, solutes are released from sample matrix to solvent (Alupului; 2012).

\section{Advantages and disadvantages}

MAE method is less consuming time, solvent, and has a special heating mechanism (Heng et al., 2013). It's a noncostly method. However, the operating temperature of this technique is relatively high $\left(100-150^{\circ} \mathrm{C}\right)$, which causes problems when used for the extraction of antioxidants (Reighard and Olesik; 2006). In addition, this technique presents a low yield when solutes or solvents are nonpolar and it also need stage of filtration or centrifugation to remove the solid residue of the extract (Wang and Waller; 2006).

\section{Supercritical fluid extraction (SFE)}

The supercritical fluid extraction, particularly by supercritical Carbon dioxide $\left(\mathrm{CO}_{2}\right)$ (because $\mathrm{CO}_{2}$ is close to room temperature, and it has low critical pressure that offers the possibility to operate at moderate pressures, generally between 100 and 450 bar) was introduced as an alternative to the extraction methods using solvent (Yepez; 2002 ; Temelli and Guclu-Ustundag ; 2005). Several solvents can be used for SFE, such as, hexane, pentane, butane, nitrous oxide, sulfur hexafluoride, and fluorinated hydrocarbons. Carbon dioxide is the most commonly used extraction solvent in SFE. $\mathrm{CO}_{2}$ alone is non selective but its capacity and selectivity of extraction can be improved by using a co-solvent or modifier. After the extraction co-solvent can easily be removed (Ankit; 2012).

A basic SFE system consists of the following parts: a tank of mobile phase, usually $\mathrm{CO} 2$, a pump to pressurize the gas, co-solvent vessel and pump, an oven that contains the extraction vessel, a controller to maintain the high pressure inside the system and a trapping vessel. Usually different type of meters like flow meter, dry/wet gas meter could be attached to the System (Azmir ; 2013).

\section{Advantages and disadvantages}

The advantages of using supercritical fluids for the extraction of bioactive compounds are (Lang and wai ; 2001):

The supercritical fluid has a higher diffusion coefficient and lower viscosity and surface tension than a liquid solvent, leading to more penetration to sample matrix and favorable mass transfer. Extraction time can be reduced substantially by SFE in compared with conventional methods;

The repeated reflux of supercritical fluid to the sample provides complete extraction; 
The selectivity of supercritical fluid is higher than liquid solvent as its solvation power can be tuned either by changing temperature and/or pressure;

Separation of solute from solvent in conventional extraction process can easily be bypassed by depressurization of supercritical fluid, which will save time;

SFE is a suitable method for thermo labile compound because it is operated at room temperature;

SFE uses little amount of organic solvent and considered as environment friendly; On-line coupling of SFE with chromatographic process is possible which is useful for highly volatile compounds;

The recycling and reuse of supercritical fluid is possible and thus minimizing waste generation;

SFE scale can be arranged on specific purpose from few milligram samples in laboratory to tons of sample in industries;

SFE process provides information regarding extraction process and mechanism which can be manipulated to optimize extraction process.

The major disadvantages of supercritical extraction mainly concern the economic aspect because this method is considered more expensive that traditional extraction processes (Wang and Waller; 2006). This technology requires a non-negligible energy consumption to establish the pressures and temperatures during it the different steps (extraction, separation and solvent recycling).

\section{Identification and characterization techniques}

Secondary metabolites compounds in plant extract are generally present in complex matrices at low levels. Purification methods are required for their identification and characterization. Separation techniques used to obtain the pure compound from mixture of compounds in the plant extract are Chromatographic and Non- Chromatographic techniques.

\section{Chromatographic techniques}

Chromatography is a technique for separation and/or identification of the components in a mixture. The basic principle is that components in a mixture have different tendencies to adsorb onto a surface or dis solve in a solvent. It is a powerful method in industry, where it is used on a large scale to separate and purify the intermediates and products in various syntheses.

\section{Gaz chromatography (GC)}

$\mathrm{GC}$ is most useful for the analysis of trace amounts of organically extractable, non-polar, volatile compounds and highly volatile compounds. Moreover, the use of GC-MS in the scan mode allows for non-targeted metabolic profiling and the discovery of novel compounds and metabolites (Krone et al., 2010). In GC mobile phase is gaseous. The mixture to be analyzed is vaporized into the column. The stationary phase in the column can be solid or liquid.

Gas chromatography (GC) and GC-MS with high specificity, high sensitivity, stability and small amount of sample characteristics, are unanimously accepted as the method for the analysis of volatile constituents (Jiang et al.,
2010). Moreover, the high selectivity of capillary columns enables separation of many volatile compounds simultaneously within very short time. GC-MS has limitations in the analysis of highly polar compounds due to their thermolability and low volatility (Yusuke; 2012).

\section{High performance liquid chromatography (HPLC)}

HPLC is a versatile, robust, and widely chromatographic technique used for the isolation of natural products, HPLC can separate a mixture of compounds and it is used in phytochemical and analytical chemistry to identify, quantify and purify the individual components of the mixture (Boligon and Athayde ; 2014). The biologically active entity is often present only as minor component in the extract and the resolving power of HPLC is ideally suited to the rapid processing of such multicomponent samples on both an analytical and preparative scale (Martin ; 2005). HPLC is base in the fact that certain compounds have different migration rates given a particular column and mobile phase. The extent or degree of separation is mostly determined by the choice of stationary phase and mobile phase.

Using HPLC, the compound of interest is separated or extracted to the target compound from other compounds or contaminants. To get an optimum separation of each compound, the chromatographer may choose the appropriate conditions, such as the proper mobile phase, flow rate, suitable detectors and columns base in the fact that any compound have a characteristic peak under certain chromatographic condition (Sasidharan et al., 2011)

\section{Thin-layer chromatography (TLC)}

TLC is a common method for herbal analysis because of its simplicity, rapidity and economy. A major advantage of TLC is that it can provide the light images and fluorescence images, which is one more visual parameter than Chromatograms, and also give different levels of profiles and corresponding integral data with chromatography scanning and digital processing. But TLC analysis also has short comings: low resolution, low sensitivity and the difficulty of detection of trace components, etc. (Zhang, et al., 2011).

\section{Non-chromatographic techniques \\ Phytochemical screening assay}

Phytoconstituents present in plant are called secondary metabolites. They can be detected in plant extract by different chemical test (Phytochemical screening). Phytochemical screening assay is a simple, quick, and inexpensive procedure that gives the researcher a quick answer to the various types of phytochemicals present in crude extract or active fraction from plant material.

\section{CONCLUSION}

In conclusion the conventional methods are bases on the solubility of solute from plant materials into solvent. Therefore, it often utilizes a large quantity of solvent to extract the desired solute, even though sometimes assisted with elevated temperature and mechanical stirring or shaking. With modern method, solvent consumption are reduced and a good extraction can be achieved in shorter period of time, and 
the recovered extract can have high yield and quality than that prepared by a conventional method. Methods such as SFE, MAE, and UAE are better suited for the extraction of heat labile and volatile compounds, which is not the case with the conventional methods. In all these technic the choice of the solvent depend on the nature of target compound.

\section{ACKNOWLEDGEMENT}

The authors are grateful to the Organization for Women in Sciences for the Developing World (OWSD) for the grant $<<$ fund reservation No 3240274094>>.

\section{REFERENCES}

[1] Alupului A., 2012, Microwave extraction of active principles from medicinal plants. U.P.B. Science Bulletin, Series B 74(2)

[2] Amita P., and Shalini T., 2014, Concept of standardization, extraction and pre Phytochemical screening strategies for herbal drug, Journal of Pharmacognosy and Phytochemistry 2 (5): 115-119

[3] Anees A., Abbas F., Alkarkhi M., Sufia H., Bazlul M., and Khoo W., and Dur, 2010, Optimization of Soxhlet Extraction of Herba Leonuri Using Factorial design of experiment. International journal of chemistry. 2 (1) 198-205

[4] Ankit G., Madhu N., and Vijay K., 2012, Modern extraction methods for preparation of bioactive plant extracts. International journal of applied and natural sciences (ijans) vol.1, issue 1 aug 2012 8-26

[5] Azmir J., Zaidul A., Rahman A., Sharif A., Mohamed A., Sahena B., Jahurul B., Ghafoor C., Norulaini D., and Omar B.,2013,Techniques for extraction of bioactive compounds from plant materials: A review. Journal of Food Engineering 117. 426-436 https://doi.org/10.1016/j.jfoodeng.2013.01.014

[6] Bimakr M., 2010, Comparison of different extraction methods for the extraction of major bioactive flavonoid compounds from spearmint (Mentha spicata L.) leaves. Food Bioprod Process; 1 -6.

[7] Boligon A., and Athayde M., 2014, Importance of HPLC in Analysis of Plants Extracts. Austin Chromatogr;1(3): 2

[8] Brachet A., christen P., and Venthley L.,2002, Focused microwave assisted extraction of cocaine and benzoylecgonine from cocaleaves. Phytochemical analysis .13: 162-169

https://doi.org/10.1002/pca.637

[9] Brusotti G., Cesari I., Dentamaro A., Caccialana G., and Massolini G., 2014, "Isolation and characterization of bioactive compounds from plant resources:The role of analysis in the ethnopharmacological approach". Journal of Pharmaceutical and Biomedical Analysis, 87: 218-228. https://doi.org/10.1016/j.jpba.2013.03.007

[10] Chemat F., Tomao V., and Virot M., 2008. In: Otles, S. (Ed.), Handbook of Food Analysis Instruments. Ultrasound-Assisted Extraction in Food Analysis. CRC Press, pp. 85-94

[11] Choon Yoong Cheok, Hanaa Abdel Karim Salman, Rabiha Sulaiman 2014. Extraction and quantification of saponins: A review FoodResearch International 5 (2014) 16-40 https://doi.org/10.1016/j.foodres.2014.01.057

[12] Evans W.,2002, General methods associated with the phytochemical investigation of herbal products. In Trease and Evans Pharmacognosy (15 ed.), New Delhi: Saunders (Elsevier), pp.137-148

[13] Grigonis D., Sivik P., Sandahl M., and Eskilsson C., 2005, Comparison of different extraction techniques for isolation of antioxidants from sweet grass (Hierochloe odorata). J Supercrit Fluids, 33: 223-233.

https://doi.org/10.1016/j.supflu.2004.08.006

[14] Heng Y., T an S., Yong., and Ong E., 2013. Emerging green technologies for the chemical standardization of botanicals and herbalpreparations. Trends in Analytical Chemistry, 50, 1-10 https://doi.org/10.1016/j.trac.2013.03.012

[15] Ibanez E., Herrero M., Mendiola J., Castro-Puyana M., 2012, Extraction and characterization of bioactive compounds with health benefits from marine resources: macro and micro algae, cyanobacteria, and invertebrates. In: Hayes, M. (Ed.), Marine Bioactive Compounds: Sources, Characterization and Applications. Springer, pp. 55-98 https://doi.org/10.1007/978-1-4614-1247-2_2
[16] Jadhav D., Rekha B., Gogate P., Rathod V., 2009, Extraction of vanillin from vanilla pods: A comparison st udy of conventional Soxhlet andultrasound assisted extraction. J. Food Eng. 93: 421- 426. https://doi.org/10.1016/j.jfoodeng.2009.02.007

[17] Jain T., 2009. Microwave assisted extraction for phytoconstituents - an overview. Asian Journal of Research in Chemistry 2 (1), 19-25

[18] Krone N., Hughes B., Lavery G., Stewart P., Arlt, W., Shackleton C., 2010, Gas chromatography/mass spectrometry (GC/MS) remains a preeminent discovery tool in clinical steroid investigations even in the era of fast liquid chromatography tandem mass spectrometry (LC/MS/MS). J. Steroid Biochem. Mol. Biol., 121, 496-504. https://doi.org/10.1016/j.jsbmb.2010.04.010

[19] Lang Q., Wai C., 2001, Supercritical fluid extraction in herbal and nat ural product studies-a practical review. Talanta 53 (4), 771-782. https://doi.org/10.1016/S0039-9140(00)00557-9

[20] Letellier M., and Budzinski H., 1999, Microwaveassisted extraction of organic compounds. Analusis 27 (3), 259-270

https://doi.org/10.1051/analusis:1999116

[21] Liangliang Z., Yongmei W., Dongmei W., Man X., and Jiahong C., 2011, Microwave Assisted Extraction of Polyphenols from Camellia oleifera Fruit Hull. Molecules, 16, 4428-4437 https://doi.org/10.3390/molecules 16064428

[22] Luque de Castro M., and Garcia-Ayuso L., 1998, Soxhlet extraction of solid materials: an outdated technique with a promising innovative fut ure, Analytica Chimica Acta 369110

[23] Martin M., Guiochon G., 2005, Effects of high pressure in liquid chromatography. J Chromatogr A.; 1090: 16-38 https://doi.org/10.1016/j.chroma.2005.06.005

[24] Nor Atikah Y., Saiful N., Anwaruddin H., Nor Adila M., 2015, AgarwoodEssential Oil: Study on Optimum Parameter and Chemical Compounds of Hydrodistillation Extraction. J. Appl. Sci. \& Agric., 10(5): $1-5$,

[25] Rafiee Z., Jafari S., Alami M., and Khomeiri M., microwaveassisted extraction of phenolic compounds from olive leaves; a comparison with maceration The Journal of Animal \& Plant Sciences, 21(4): 2011, Page: 738-745

[26] Reighard T., and. Olesik S., 2006, Bridging the Gap between Supercritical Fluid Extractions and Liquid Extraction Techniques: Alternative Approaches of the Extraction of Solid and Liquid Environmental Matrices, Critical Reviews in Analytical Chemistry, 26 (2\&3) 1-39

[27] Sasidharan S., Chen., Saravanan K., Sundram L., Yoga L., Extraction, isolation and characterization of bioactive compounds from plants' extracts. Afr J Tradit Complement Altern Med. (2011) 8(1):1-10 1

[28] SilvaV., Nelson D., Drummond M., Dufosse L., Gloria M., 2005, Comparison of hydrodistillation methods for the deodorization of turmeric. Food Research International 38 (8-9), 1087-1096 https://doi.org/10.1016/j.foodres.2005.02.025

[29] Smith R., 2003, Before the injection-modern methods of sample preparation for separation techniques. Journal of Chromatography A 1000 (1-2), 3-27. https://doi.org/10.1016/S0021-9673(03)00511-9

[30] Takeuchi T.,Pereira C., Braga M., Maróstica M., Leal P., and Meireles M., 2009, Low-pressure solvent extraction (solid-liquid extraction, microwave assisted, and ultrasound assisted) from condimentary plants. In M. A. A. Meireles (Ed.), Extracting bioactive compounds for food products - Theory and applications (pp. 140-144). Boca Raton: CRC Press, 151158

[31] Tang-Bin Z., Min W., Ren-You G., and Wen-Hua L., 2011, Optimization of ultrasoundassisted extraction of anthocyanins from mulberry, using response surface methodology. Int. J. Mol. Sci. 12, 3006-3017 https://doi.org/10.3390/ijms 12053006

[32] https://doi.org/10.1002/047167849X https://doi.org/10.1002/047167849X

[33] Tonthubthimthong P., Chuaprasert S., Douglas P., Luewisut thichat W., 2001, Supercritical CO2 extraction of nimbin from neem seeds an experimental study. J. Food Eng. 47: 289293 https://doi.org/10.1016/S0260-8774(00)00131-X

[34] Wang L., and Waller C., 2006, Recent advances in extraction of nutraceuticals from plants, Trends in Food Science \& Technology, 17, $300-312$. https://doi.org/10.1016/j.tifs.2005.12.004

[35] Yepez B., Espinosa M., López S., and Bolaños G.,002, producing antioxidant fractions from herbaceous matrices by supercritical fluid extraction, Fluid Phase Equilibria 879-884 
[36] Yusuke I., Takahiro S., Kentaro H., Akihito O., Yuri T., $\quad$ Kyohei N., Rie I., Koichi S., and Hiroyuki N.,2012, Separation Technique for the Determination of Highly Polar Metabolites in Biological Samples. Metabolites, 2, 496-515 https://doi.org/10.3390/metabo2030496

[37] Zhang Y., Sun S., Dai J., Wang W., Cao Huijuan, Wu J., and Gou X., 2011, Quality Control Method for Herbal Medicine - Chemical Fingerprint Analysis, Quality Control of Herbal Medicines and Related Areas, Prof. Yukihiro Shoyama (Ed.), ISBN: 978-953-307-682 